BMJ Open Diabetes Research \& Care

\title{
Obesity independently predicts responders to biphasic insulin 50/50 (Humalog Mix50 and Insuman Comb 50) following conversion from other insulin regimens: a retrospective cohort study
}

\author{
J Mamza, ${ }^{1}$ R Mehta, ${ }^{2}$ I Idris ${ }^{1}$
}

To cite: Mamza J, Mehta R, Idris I. Obesity independently predicts responders to biphasic insulin 50/50 (Humalog Mix50 and Insuman Comb 50) following conversion from other insulin regimens: a retrospective cohort study. BMJ Open Diabetes Research and Care 2014;2:e000021.

doi:10.1136/bmjdrc-2014000021

Received 6 February 2014 Revised 9 April 2014 Accepted 21 April 2014
CrossMark

\begin{abstract}
${ }^{1}$ Division of Medical Sciences \& Graduate Entry Medicine, School of Medicine, University of Nottingham, Derby, UK

${ }^{2}$ Trent Research Design Services, University of Nottingham, Nottingham, UK
\end{abstract}

Correspondence to Dr Iskandar Idris; Iskandar.idris@nottingham. ac.uk

\section{ABSTRACT}

Aims: This study aims to examine the metabolic effects of intensification or initiation of insulin treatment with biphasic insulin 50/50, and determine the predictors of responders or non-responders to biphasic insulin 50/50.

Methods: A cohort of 2183 patients $\geq 18$ years with diabetes, newly treated with biphasic insulin 50/50 between January 2000 and May 2012, were sourced from UK General Practices via The Health Improvement Network (THIN) database. Baseline clinical parameters of 1267 patients with suboptimal glycated hemoglobin $(\mathrm{HbA1c})>7.5 \%$ (>58 mmol $/ \mathrm{mol}$ ) who had received background insulin regimens for at least 6 months preceding biphasic insulin 50/50 were compared against 12-month outcome data. Responders were defined as those with $\mathrm{HbA} 1 \mathrm{c}<7.5 \%(58 \mathrm{mmol} / \mathrm{mol})$ and $/$ or $\mathrm{HbA} 1 \mathrm{c}$ reduction of $\geq 1 \%(10.9 \mathrm{mmol} / \mathrm{mol})$ at 12 months. Comparative analyses were carried out on subgroups of 237 patients initiating insulin therapy with biphasic insulin 50/50, and between users of the Humalog Mix50 (HM50) versus Insuman Comb 50 (IC50). Associations were examined using t tests and multivariate logistic regression techniques.

Results: The overall mean $\mathrm{HbA1c}$ reduction at 12 months as a result of intensification and initiation with biphasic insulin $50 / 50$ was $0.5 \%(5.5 \mathrm{mmol} / \mathrm{mol})$ and $1.6 \%(17.5 \mathrm{mmol} / \mathrm{mol})$, respectively. Adjusted ORs show obesity (body mass index $>30 \mathrm{~kg} / \mathrm{m}^{2}$ ), treatment duration for $\geq 9$ months, and baseline $\mathrm{HbA} 1 \mathrm{c}$ are independent determinants of responders. In addition, stratified for baseline $\mathrm{HbA1c}$ levels, HM50 was associated with better HbA1c outcome compared with IC50.

Conclusions: biphasic insulin 50/50 is effective for achieving glycemic control in suboptimal $\mathrm{HbA} 1 \mathrm{c}$ levels, especially among obese patients with insulin-treated diabetes. Stratified for baseline HbA1c, HM50 was associated with improved $\mathrm{HbA1C}$ outcome compared with IC50.

\section{INTRODUCTION}

The introduction of insulin therapy to achieve adequate glycemic control in patients with type 2 diabetes mellitus (T2DM) is

\section{KEY MESSAGES}

- Limited data are available to determine the appropriate place of use for premixed biphasic insulin 50/50 (Humalog Mix50 and Insuman Comb 50 ) in routine clinical practice, compared with other lower mix insulin formulations (eg, mix30 or mix25)

- Using real-world clinical data from a UK primary care cohort, we have shown that biphasic insulin $50 / 50$ is effective for achieving glycemic control in suboptimal glycated hemoglobin $(\mathrm{HbA} 1 \mathrm{c})$ levels, especially among obese (body mass index $>30$ ) patients with insulin-treated diabetes.

- Humalog Mix50 is more effective than Insuman Comb 50 .

- These findings could form a basis for a randomized clinical trial on obese insulin-treated patients with diabetes.

inherent to the progressive deterioration of the pancreatic $\beta$-cell function. ${ }^{12}$ There is no consensus about the most appropriate insulin regimen to be chosen, ${ }^{3}$ but National Institute for Health and Care Excellence (NICE) guidelines recommend initiating insulin therapy with human neutral protamine Hagedorn insulin or a long-acting analog (basal insulin) injected at bedtime or twice daily according to the patient's need. ${ }^{4}$ When glycemic control is inadequate with basal insulin, therapy can be intensified with prandial insulin (which may include a premixed therapy or basal-bolus regimen). Basal-bolus insulin has been shown to be useful for controlling preprandial and postprandial blood glucose levels, as well as for lowering glycated hemoglobin (HbA1c) levels, ${ }^{5} 6$ although we have shown that in routine practice, glycemic control remains suboptimal in many patients receiving a basal-bolus insulin regimen. ${ }^{7}$

In people without diabetes, basal insulin secretion represents approximately $50 \%$ of 
the total secretion, with the remaining $50 \%$ being meal related. ${ }^{8}$ Among patients with T2DM requiring intensive insulin therapy regimens in the form of multiple daily injections or insulin pump therapy, both regimens required $50 \%$ basal and $50 \%$ rapid-acting insulin following dose titration. ${ }^{9}$ Based on these, a biphasic insulin $50 / 50$ containing $50 \%$ each of rapid-acting and basal insulin (a mid-mix regimen) was developed to provide the physiological advantages of rapid-acting and longacting insulin in the convenience of a premixed formulation. ${ }^{10}$ Indeed, intensification of insulin therapy (where patients' blood glucose levels remain suboptimal after receiving biphasic insulin aspart 30/70, biphasic human insulin $30 / 70$, or biphasic insulin lispro 25/75) has been shown to be achieved by switching to premixed regimens with greater prandial coverage (HM50). ${ }^{11-13}$ Insuman Comb 50 (IC50)- a combination of $50 \%$ soluble insulin and $50 \%$ crystalline protamine insulinis also available as a biphasic insulin 50/50 regimen. There is, however, limited postmarket surveillance and/ or real-world evidence assessing the effectiveness of switching to HM50 or IC50 regimens in patients with suboptimal HbA1c levels. This study aims to investigate the effectiveness of the biphasic insulin 50/50 regimen (HM50 and IC50) in patients with persistently suboptimal HbA1c and examine the clinical and metabolic parameters that predict glycemic response in people with T2DM.

\section{METHODS}

\section{Study design and data source}

We conducted a retrospective cohort analysis of data from The Health Improvement Network (THIN) database, which contains anonymous patient data from more than 400 general practices throughout England and Wales. The database has been validated at the practice and dataset levels by comparing its demographics, morbidity, mortality, prevalence, and geographical rates with various national data sources. The database contains information on all past and current medical diagnoses (coded using read codes) and prescribed medications (coded using British National Formulary).

\section{Study population}

The study population comprises a cohort of patients who were identified to have T2DM, and were registered to a practice for more than 12 months before the index date (ie, between January 1, 2000 and the end of the study - May 16, 2012). The cohort comprised patients with a suboptimal glucose control (HbA1c) level above $7.5 \%(58 \mathrm{mmol} / \mathrm{mol})$, who were prescribed other forms of insulin regimens before the index date and were $\geq 18$ years. Standardized computerized routines to include programing language and use of algorithms were used to obtain the relevant data using Read codes. Information was extracted on patients diagnosed with diabetes and previous insulin prescriptions for at least
6 months preceding conversion to biphasic insulin 50/50 regimen. Six months duration was used because THIN data suggests $95 \%$ of repeat prescriptions for insulin have a periodicity of less than 6 months.

\section{Exposure and outcomes}

Exposure was defined as two or more prescriptions of HM50 or IC50, with a follow-up period of 12 months from the index date. Alternatively, the 90th day recording of HbAlc levels was used, or the date of switching to, or adding another glucose-lowering drug. The primary outcome was a change in HbAlc levels after exposure. Responders are defined as patients whose 12-month HbAlc fell below $7.5 \%$ ( $58 \mathrm{mmol} / \mathrm{mol}$ ) or who experienced $\mathrm{HbAlc}$ reduction of more than $1 \%$ $(10.9 \mathrm{mmol} / \mathrm{mol})$ at 12 months when compared with baseline. The secondary outcome was a measure of the association between changes in HbA1c level and absolute change in weight at 12 months after the index date.

\section{Covariates}

Covariates were selected a priori on the basis of clinical significance. These are baseline demographic and clinical parameters, referred to as 'predictors' of interest. They include age, gender, social deprivation (measured using Townsends index scores),${ }^{14}$ body weight, body mass index (BMI), baseline HbAlc, total cholesterol levels, low-density lipoprotein, high-density lipoprotein (HDL), triglycerides, systolic and diastolic blood pressures, smoking status, lipid-lowering therapies, antihypertensive drugs, aspirin, oral antidiabetic drugs (OADs), drugs, duration of diabetes drug treatment, and comorbidity. In addition, the background insulin treatments the patients received prior to index date, for example, basal, bolus, or premixed regimens, were included as determinants of interest.

\section{Statistical analysis}

Baseline characteristics that might distinguish between responders and non-responders to HM50/IC50 therapy were analyzed using the $\chi^{2}$ and $\mathrm{t}$ tests. Multiple logistic regressions were carried out to identify covariates that predict a response (HbAlc change) within 12 months. ORs for predictors and confounding variables were calculated and expressed as point estimates with a 95\% CI, at the conventional statistical significance level of 0.05 . Missing data were accounted for with multiple imputations using chained equations. ${ }^{15}$

\section{Subgroup and secondary analyses}

Correlation and linear regression analyses were performed to assess the relationship between changes in HbAlc and weight at 12 months. Analysis was carried out on a subgroup of patients who were not prescribed any insulin prior to study entry (initiation group). Subgroup analysis for efficacy in end point changes in HbAlc from baseline was performed between HM50 and IC50 treatment groups. Baseline HbAlc was 
categorized into three strata: $<8 \%(<64 \mathrm{mmol} / \mathrm{mol}), 8$ to $<9 \%(64-75 \mathrm{mmol} / \mathrm{mol})$, and $\geq 9 \%(\geq 75 \mathrm{mmol} / \mathrm{mol})$.

\section{Sensitivity analysis}

Sensitivity analysis was carried out to compare results of multiply imputed data with complete data, and to assess the reliability of the outcomes and the impact of missing data. All analyses were conducted using Stata Software, V.13. ${ }^{16}$

\section{Bias}

Our analysis employed the 'new user' design to minimize biases associated with prevalent use of insulin. ${ }^{17}$ Prior exposure to basal, bolus, and other premixed insulin regimens could also be a factor on the causal pathway for response, thereby introducing confounding by indication. ${ }^{18}$ These potential biases were minimized by conducting analysis within a cohort of new users who did not receive prescriptions for biphasic insulin $50 / 50$ in the 12 months prior to study entry. The cohort was restricted to patients with at least two repeat prescriptions of biphasic insulin 50/50 for an estimated 12-month follow-up to reduce the risk of bias introduced by the different durations of treatments. ${ }^{17} \mathrm{We}$ also restricted the cohort to individuals whose treatment with insulin for at least 6 months preceding conversion had failed.

\section{RESULTS}

\section{General patient characteristics}

Of the 2183 users of biphasic insulin 50/50, 1267 patients fulfilled the criteria for cohort entry as outlined in figure 1 and 237 people formed the subgroup of patients who had not received insulin prior to the index date. The cohort had a mean age of 61 years and $54 \%$ were men. In total, $684(54 \%)$ of the cohort were prescribed HM50.

\section{Response to intensification therapy}

Our analysis focused on HbAlc response to intensification with biphasic insulin 50/50. In total, $457(36 \%)$ of patients responded to intensification therapy, based on criteria for responders described previously. Responders were not significantly different with age, sex, weight, social deprivation strata, smoking status, or previously prescibed medications. In addition, responders were unrelated to the majority of comorbid conditions and clinical parameters. Baseline mean HbAlc was significantly higher among responders compared with nonresponders $(10.2 \%(88 \mathrm{mmol} / \mathrm{mol})$ vs $9.3 \%$ ( $78 \mathrm{mmol} /$ mol), $\mathrm{p}<0.001)$, and responders had a slightly lower HDL at baseline ( 1.3 vs $1.4 \mathrm{mmol} / \mathrm{L}, \mathrm{p}=0.03$; table 1$)$. Overall, intensification with biphasic insulin $50 / 50$ resulted in a $0.5 \%(5.5 \mathrm{mmol} / \mathrm{mol})$ reduction in $\mathrm{HbAlc}$, $0.9 \mathrm{~kg}$ increase in weight, and $0.3 \mathrm{~kg} / \mathrm{m}^{2}$ increase in BMI at 12 months. Responders had a significantly
Figure 1 Study selection flow diagram. HbA1c, glycated hemoglobin; T2DM, type 2 diabetes mellitus.

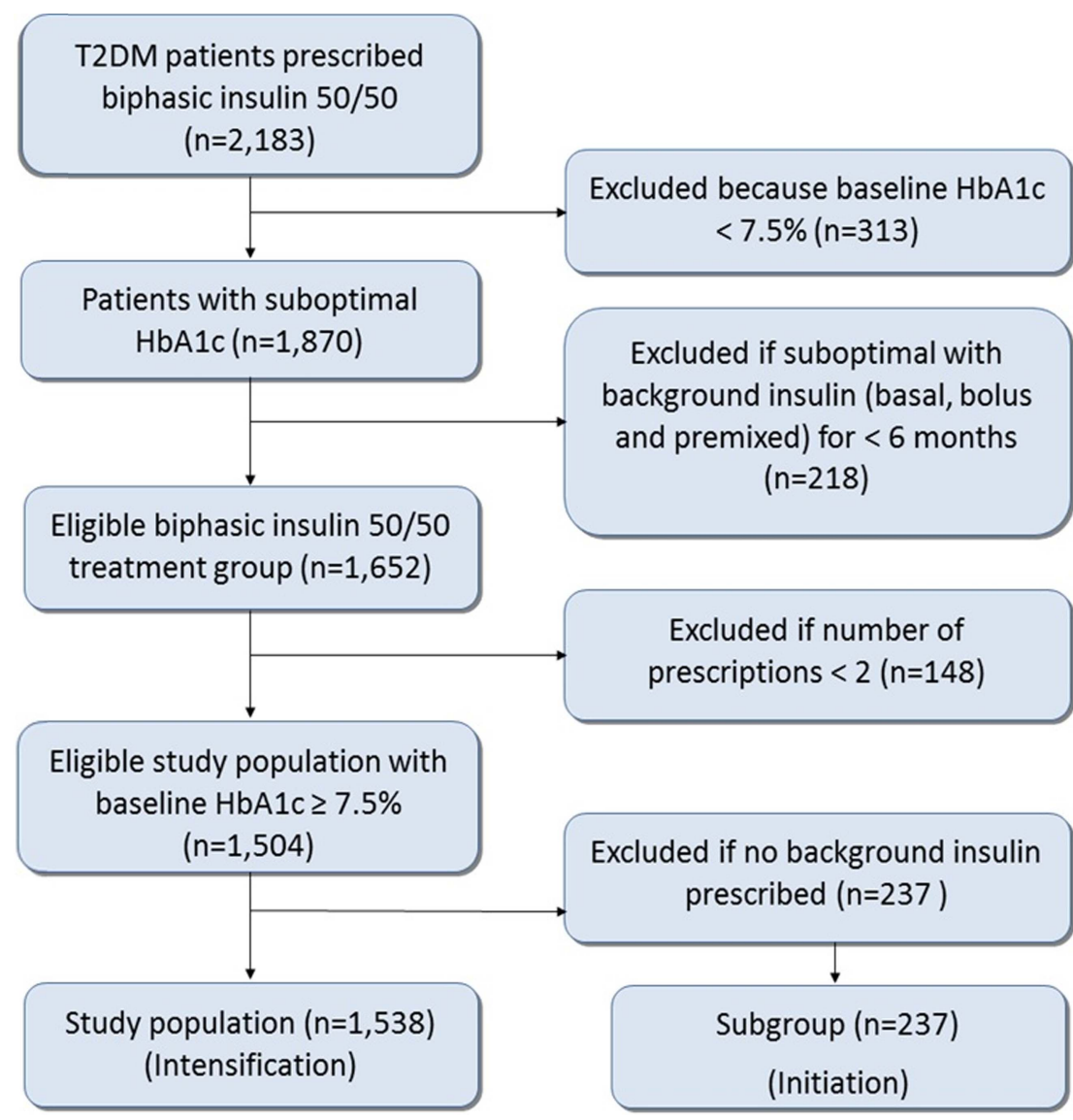


Table 1 Baseline characteristics of Humalog Mix50 users

\begin{tabular}{|c|c|c|c|c|c|}
\hline Characteristics & $\begin{array}{l}\text { Total } \\
(n=1267)\end{array}$ & $\begin{array}{l}\text { Responders } \\
(n=457)\end{array}$ & $\begin{array}{l}\text { Non-responders } \\
(n=810)\end{array}$ & $\begin{array}{l}\text { OR (95\% Cl) } \\
\text { (unadjusted) }\end{array}$ & p Value \\
\hline \multicolumn{6}{|l|}{ Exposure/predictors } \\
\hline Age (years) & $61(15)$ & $62(14)$ & $61(15)$ & 1.01 (1.00 to 1.01$)$ & 0.1 \\
\hline \multicolumn{6}{|l|}{ Sex } \\
\hline Male & $682(54)$ & $251(37)$ & $431(63)$ & 1 & \\
\hline Female & $585(46)$ & $206(35)$ & $379(65)$ & $0.93(0.74$ to 1.17$)$ & 0.9 \\
\hline \multicolumn{6}{|l|}{ Townsend deprivation } \\
\hline I-least deprived & $226(18)$ & $84(37)$ & $142(63)$ & 1 & \\
\hline II & $269(21)$ & $94(35)$ & $175(65)$ & $0.91(0.63$ to 1.31$)$ & 0.6 \\
\hline III & $284(22)$ & $103(36)$ & $181(64)$ & $0.96(0.67$ to 1.38$)$ & 0.8 \\
\hline IV & 274 (22) & 94 (34) & $180(66)$ & $0.88(0.61$ to 1.27$)$ & 0.5 \\
\hline V-most deprived & $214(17)$ & $82(38)$ & $132(62)$ & $1.05(0.71$ to 1.54$)$ & 0.8 \\
\hline BMI $\left(\mathrm{kg} / \mathrm{m}^{2}\right)$ & $30.4(6.8)$ & $31(6.9)$ & $30(6.7)$ & 1.02 (1.00 to 1.04$)$ & 0.01 \\
\hline \multicolumn{6}{|l|}{ BMI categories $\left(\mathrm{kg} / \mathrm{m}^{2}\right)$} \\
\hline Normal & $259(20)$ & $79(31)$ & $180(70)$ & 1 & \\
\hline Overweight & $406(32)$ & 140 (34) & $266(66)$ & $1.20(0.86$ to 1.68$)$ & 0.3 \\
\hline Obese & $602(48)$ & $238(40)$ & $364(40)$ & 1.49 (1.09 to 2.03$)$ & 0.01 \\
\hline Weight (kg) & 85.8 (2.) & 87 (20) & $85(20)$ & $1.00(1.00$ to 1.01$)$ & 0.1 \\
\hline Baseline HbA1c (\%) & $9.6(1.5)$ & $10.2(1.7)$ & $9.3(1.3)$ & 1.54 (1.41 to 1.68$)$ & $<0.001$ \\
\hline \multicolumn{6}{|l|}{$\mathrm{BP}(\mathrm{mm} \mathrm{Hg})$} \\
\hline Systolic BP & $139(19)$ & 139 (19) & $139(19)$ & $1.00(1.00$ to 1.01$)$ & 0.6 \\
\hline Diastolic BP & $76(11)$ & $76(11)$ & $76(11)$ & $1.00(1.00$ to 1.01$)$ & 0.6 \\
\hline Total cholesterol (mmol/L) & 4.7 (1.3) & 4.7 (1.3) & $4.7(1.2)$ & 1.01 (0.92 to 1.10$)$ & 0.9 \\
\hline $\mathrm{HDL}(\mathrm{mmol} / \mathrm{L})$ & $1.3(0.6)$ & $1.3(0.6)$ & $1.4(0.5)$ & 0.78 (0.63 to 0.98$)$ & 0.03 \\
\hline LDL (mmol/L) & $2.6(1.1)$ & $2.6(1.1)$ & $2.6(1.1)$ & $1.02(0.92$ to 1.14$)$ & 0.7 \\
\hline Triglyceride (mmol/L) & $2.4(6.6)$ & 2.7 (4.9) & $2.2(7.3)$ & 1.01 (0.99 to 1.03$)$ & 0.2 \\
\hline \multicolumn{6}{|l|}{ Smoking status } \\
\hline Never smoked & $577(46)$ & $204(35)$ & $373(65)$ & 1 & \\
\hline Current smoker & $226(18)$ & 76 (34) & $150(66)$ & $0.93(0.67$ to 1.28$)$ & 0.6 \\
\hline Ex-smoker & $464(37)$ & $177(38)$ & $287(62)$ & $1.13(0.87$ to 1.45$)$ & 0.9 \\
\hline \multicolumn{6}{|l|}{ Use of medications } \\
\hline Antihypertensive & $1076(85)$ & $381(35)$ & $695(65)$ & $1.83(0.61$ to 1.13$)$ & 0.2 \\
\hline Lipid-lowering therapy & $911(72)$ & $341(37)$ & $570(63)$ & $1.24(0.96$ to 1.60$)$ & 0.1 \\
\hline Aspirin & $693(55)$ & $255(37)$ & $438(63)$ & 1.07 (0.85 to 1.35$)$ & 0.5 \\
\hline \multicolumn{6}{|l|}{ Oral antidiabetic } \\
\hline Gliptin & $44(3)$ & $16(36)$ & $28(63)$ & $1.01(0.54$ to 1.89$)$ & 0.9 \\
\hline GLP1 & $61(5)$ & $25(41)$ & $36(59)$ & 1.24 (0.73 to 2.10$)$ & 0.4 \\
\hline Metformin & $1115(88)$ & $400(36)$ & $715(64)$ & 0.93 (0.66 to 1.32$)$ & 0.7 \\
\hline Sulfonylurea & 465 (37) & $177(38)$ & $288(62)$ & $1.15(0.90$ to 1.45$)$ & 0.3 \\
\hline Thiazolidinedione & $133(11)$ & 49 (37) & $84(63)$ & $1.04(0.72$ to 1.51$)$ & 0.8 \\
\hline Other & $95(8)$ & $35(37)$ & $60(63)$ & $1.03(0.67$ to 1.60$)$ & 0.9 \\
\hline \multicolumn{6}{|l|}{ Previous insulin therapy } \\
\hline Premixed regimen & $925(73)$ & $325(35)$ & $600(65)$ & 1 & \\
\hline Basal insulin & $253(20)$ & $95(38)$ & $158(62)$ & $1.11(0.83$ to 1.48$)$ & 0.5 \\
\hline Bolus & $89(7)$ & 37 (42) & $52(58)$ & 1.31 (0.84 to 2.05$)$ & 0.2 \\
\hline \multicolumn{6}{|l|}{ Comorbid conditions } \\
\hline $\mathrm{CHD}$ & $636(50)$ & 237 (37) & $399(63)$ & $1.11(0.88$ to 1.40$)$ & 0.4 \\
\hline PAD & $313(25)$ & $120(38)$ & $193(62)$ & $1.14(0.87$ to 1.48$)$ & 0.3 \\
\hline Cerebrovascular & $252(20)$ & 87 (35) & $165(65)$ & $0.92(0.69$ to 1.28$)$ & 0.6 \\
\hline Heart failure & $228(18)$ & $96(42)$ & $132(58)$ & 1.37 (1.02 to 1.83$)$ & 0.04 \\
\hline Hypoglycemia & $549(43)$ & $193(35)$ & $356(65)$ & $0.93(0.74$ to 1.18$)$ & 0.6 \\
\hline \multicolumn{6}{|l|}{ Number of Mix50 Rx } \\
\hline $2-5$ & $406(32)$ & $131(32)$ & $275(68)$ & 1 & \\
\hline $6-8$ & $315(25)$ & $95(30)$ & $220(70)$ & $0.91(0.66$ to 1.25$)$ & 0.5 \\
\hline $9-12$ & $284(22)$ & $104(37)$ & $180(63)$ & 1.21 (0.88 to 1.67$)$ & 0.2 \\
\hline$\geq 13$ & $262(21)$ & $127(48)$ & $135(52)$ & 1.97 (1.43 to 2.72$)$ & $<0.001$ \\
\hline
\end{tabular}


Table 1 Continued

\begin{tabular}{|c|c|c|c|c|c|}
\hline Characteristics & $\begin{array}{l}\text { Total } \\
(n=1267)\end{array}$ & $\begin{array}{l}\text { Responders } \\
(n=457)\end{array}$ & $\begin{array}{l}\text { Non-responders } \\
(\mathrm{n}=\mathbf{8 1 0})\end{array}$ & $\begin{array}{l}\text { OR (95\% Cl) } \\
\text { (unadjusted) }\end{array}$ & p Value \\
\hline \multicolumn{6}{|c|}{ Duration of therapy (months) } \\
\hline $0-3$ & $111(9)$ & $27(24)$ & $84(76)$ & 1 & \\
\hline $3-6$ & $106(8)$ & $33(31)$ & 73 (69) & $1.41(0.77$ to 2.56$)$ & 0.3 \\
\hline $6-9$ & $133(11)$ & $48(36)$ & $58(64)$ & 1.76 (100 to 3.07$)$ & 0.05 \\
\hline $9-12$ & $917(72)$ & $349(38)$ & $568(62)$ & $1.91(1.21$ to 3.01$)$ & 0.005 \\
\hline
\end{tabular}

BMI, body mass index; BP, blood pressure; CHD, coronary heart disease; GLP1, glucagon-like peptide-1 agonis;

$\mathrm{HbA1c}$; glycated hemoglobin; HDL, high-density lipoprotein; LDL, low-density lipoprotein; PAD, peripheral artery disease.

higher mean $(\mathrm{SD})$ weight increase $(1.6(7.1)$ vs $0.5(4.9)$ $\mathrm{kg}, \mathrm{p}<0.001)$ and significant mean $\mathrm{HbA1c}$ reduction of $1.9 \% \quad(20.8 \mathrm{mmol} / \mathrm{mol}) \quad$ vs $\quad 0.3 \% \quad(3.3 \mathrm{mmol} / \mathrm{mol})$ increase seen in non-responders $(\mathrm{p}<0.001)$.

\section{Main results}

After adjusting for the effects of confounders, the independent predictors of response to intensification with biphasic insulin $50 / 50$ were obesity (BMI $>30 \mathrm{~kg} / \mathrm{m}^{2}$; OR, 1.50 (95\% CI 1.08 to 2.09 ), $\geq 9$ months of intensification therapy (OR, 1.98 (95\% CI 1.23 to 3.20)), and baseline HbAlc (OR, 1.55 (95\% CI 1.42 to 1.69); table 2).

\section{Comparison between HIM50 vs IC50}

We compared the metabolic effects of HM50 vs IC50 according to baseline strata for HbAlc values. Overall, HM50 was associated with a better HbAlc response compared with IC50 (mean reduction in HbA1c of $0.6 \%$ vs $0.4 \%$ (6.6 vs $4.4 \mathrm{mmol} / \mathrm{mol}$ ), $\mathrm{p}<0.001$; table 3 ). The difference in mean change of HbAlc was approximately $0.5 \%(95 \%$ CI $0.02 \%$ to $0.94 \%)$ or $5.5 \mathrm{mmol} / \mathrm{mol}(95 \%$ CI 0.2 to 10.3) lower with HM50 treatment group compared with IC50 in the baseline HbA1c category below $8 \% \quad(<64 \mathrm{mmol} / \mathrm{mol})$. The IC50 group had a $0.06 \%(95 \%$ CI $-0.22 \%$ to $0.34 \%)$ or $0.7 \mathrm{mmol} / \mathrm{mol}$ (95\% CI 2.4 to 3.7) lower reduction in HbA1c compared with HM50 at baseline HbA1c category of $8 \%$ to $<9 \%$ (64 to $<75 \mathrm{mmol} / \mathrm{mol}$ ). The greatest treatment benefit was observed in patients within the baseline HbAlc category of $9 \%$ and above $(\geq 75 \mathrm{mmol} / \mathrm{mol})$, where HM50 was associated with a non-significant lower mean difference $(-0.2 \% \quad(95 \% \quad$ CI $-0.03 \%$ to $0.39 \%)$ or $-2.2 \mathrm{mmol} / \mathrm{mol}(95 \% \mathrm{CI}-0.3$ to 4.3$)$ ) when compared with the IC50 treatment group. Mean weight increase at 12 months was not significantly different between HM50 and IC50 users (table 3).

\section{Other analyses}

Tests for interactions between sex, social deprivation, and responders were not significant at the $5 \%$ level, indicating no evidence of effect modification across these groups. A scatter plot of individual patient data shows a significantly negative but weak association between change in HbAlc and change in weight at 12 months

Table 2 Results of multiple logistic regression analyses

\begin{tabular}{|c|c|c|c|c|}
\hline Predictors of response & OR $(95 \% \mathrm{Cl})$ (unadjusted) & p Value & OR (95\% Cl) (adjusted) & LRT $p$ Value \\
\hline Baseline HbA1c (\%) & $1.53(1.40$ to 1.67$)$ & $<0.001$ & $1.55(1.42$ to 1.69$)$ & $<0.001$ \\
\hline \multicolumn{5}{|l|}{ BMI categories $\left(\mathrm{kg} / \mathrm{m}^{2}\right)$} \\
\hline Normal & 1 & & 1 & \\
\hline Overweight & $1.35(0.94$ to 1.94$)$ & 0.1 & 1.40 (0.98 to 2.00$)$ & 0.06 \\
\hline Obese & $1.35(0.95$ to 1.91$)$ & 0.09 & 1.50 (1.08 to 2.09$)$ & 0.02 \\
\hline $\mathrm{HDL}(\mathrm{mmol} / \mathrm{L})$ & 0.91 (0.70 to 1.12$)$ & 0.3 & - & - \\
\hline \multicolumn{5}{|l|}{ Comorbid conditions } \\
\hline Heart failure & $1.20(0.88$ to 1.64$)$ & 0.2 & - & - \\
\hline \multicolumn{5}{|l|}{ Number of Mix50 Rx } \\
\hline $2-5$ & 1 & & - & - \\
\hline $6-8$ & $0.72(0.50$ to 1.04$)$ & 0.08 & & \\
\hline $9-12$ & 0.94 (0.64 to 1.37$)$ & 0.7 & & \\
\hline$\geq 13$ & $1.27(0.85$ to 1.91$)$ & 0.2 & & \\
\hline \multicolumn{5}{|c|}{ Duration of therapy (months) } \\
\hline $0-3$ & 1 & & 1 & \\
\hline $3-6$ & 1.64 (0.88 to 3.04$)$ & 0.1 & 1.51 (0.80 to 2.82$)$ & 0.2 \\
\hline $6-9$ & 1.90 (1.05 to 3.44$)$ & 0.04 & 1.70 (0.94 to 3.07$)$ & 0.08 \\
\hline $9-12$ & 1.95 (1.15 to 3.31$)$ & 0.01 & 1.98 (1.23 to 3.20$)$ & 0.005 \\
\hline
\end{tabular}

BMI, body mass index; HDL, high-density lipoprotein; HbA1c; glycated hemoglobin; LRT, likelihood ratio test. 


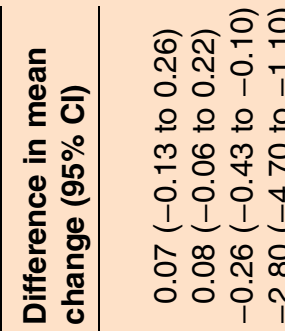

(ิ) สิธ

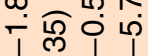

웅ㅇㅇ

응유순으

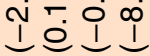

วิธิ์

送宅宅

के ํํㅇ

广०

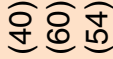

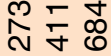

的

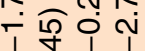

$\circ 0$ 응

今ิ으워ำ

i cil

ริำ

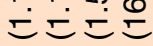

б ले ले 8

i०

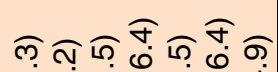

こ艺こ壬こ元

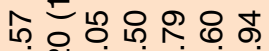

0.00
0

त్

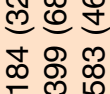

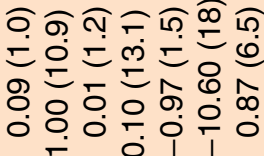

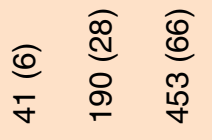

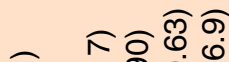

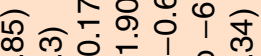
00 응ㅇㅇㅇㅇㅛ

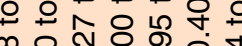

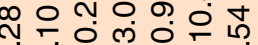

0 ल 11110

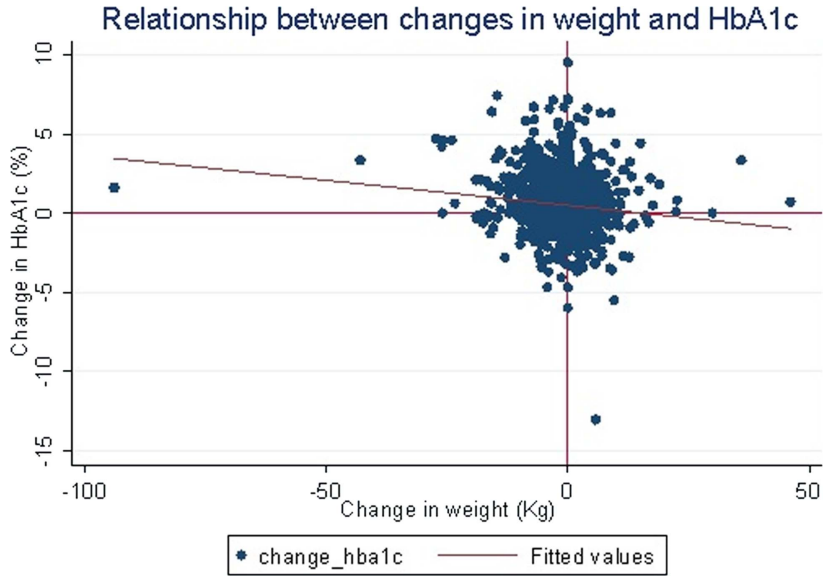

Figure 2 Relationship between change in glycated hemoglobin (HbA1c) and change in weight at 12 months.

(Pearson's correlation coefficient, $\mathrm{r}=-0.13$; $\mathrm{p}<0.001$; figure 2). Change in weight accounts for approximately $1.7 \%$ of the total variation in HbAlc change, and for every unit increase in weight, HbA1c increased by an estimated $0.04 \%(0.4 \mathrm{mmol} / \mathrm{mol})$. The subgroup of 237 patients who initiatied insulin therapy with biphasic insulin 50/50 were examined, and 149 (59\%) patients responded to treatment. The mean (SD) reduction in HbA1c in the subgroup was $1.6(2.1) \%$ or 17.5 (23.0) $\mathrm{mmol} / \mathrm{mol}$.

\section{DISCUSSION}

Overall, this study showed a significant $0.5 \%(5.5 \mathrm{mmol} /$ mol) reduction in $\mathrm{HbAlc}$ at 12 months after patients with suboptimal HbAlc from background insulin were converted to biphasic insulin 50/50. Multiple regression analysis showed that the presence of obesity and baseline HbA1c were independent predictors of responders to biphasic insulin 50/50 therapy. Results showed that responders to biphasic insulin 50/50 in the main study cohort were more likely to experience weight gain and reduction in cholesterol levels, compared with nonresponders. HM50 appears to be superior to IC50 in glycemic outcomes, when stratified for baseline HbAlc.

Although mean HbA1c improved following conversion to biphasic insulin 50/50, only $36 \%$ of patients responded to the intensification based on our strict definition of responders. This relatively low percentage of responders to biphasic insulin 50/50 may reflect the difficulties in lowering HbAlc in a challenging cohort of patients with insulin-treated diabetes. This was similar to our previous study of responders to any insulin therapy among patients with newly diagnosed diabetes, where $47 \%$ of patients responded to any insulin therapy. ${ }^{19}$

The link between intensification of insulin treatment and weight gain is well recognized. ${ }^{6}{ }^{20} \mathrm{We}^{7}$ and others ${ }^{21}{ }^{22}$ have previously shown that low BMI is a significant predictor of response to insulin therapy. A study by Nichols et al on insulin-treated patients with T2DM, for example, 
showed that lower BMI, younger age, and female gender were predictors of good glycemic response to insulin. Furthermore, we have previously shown a threshold BMI of $34.7 \mathrm{~kg} / \mathrm{m}^{2}$, above which patients appeared to have a reduced response to insulin therapy. ${ }^{7}$ Thus, the management of obese insulin-treated diabetes presents a significant therapeutic challenge as clinicians strive to achieve optimal glycemic targets. To this end, a novel and important finding from this study was the observation of improved HbAlc response to biphasic insulin 50/50, among obese (BMI $>30 \mathrm{~kg} / \mathrm{m}^{2}$ ) compared with non-obese patients with insulin-treated diabetes. The reason for this is unclear, as our data cannot be analyzed for the total amount or frequency of insulin being used per day. We would speculate, however, that the intensification of insulin therapy by conversion to biphasic insulin 50/50 regimen (from a basal-bolus insulin or a low-mix biphasic insulin regimen) is often associated with a reduction in the total amount of insulin used per day (unpublished preliminary observation from our ongoing UK multicentre audit of HM50 use in clinical practice), which would facilitate weight loss, improved compliance, and would confer glycemic benefits. This is highly relevant given the high prevalence of obesity among insulin-treated patients with diabetes. The mean weight gain of $1.6 \mathrm{~kg}$ at 1 year induced by conversion to biphasic insulin $50 / 50$ was comparable, if not slightly less than the weight gain of $2.2 \mathrm{~kg}$ with any insulin regimen, observed in our previous study. ${ }^{7}$ Moreover, in the previous study, ${ }^{7}$ we observed a mean BMI increase of $1.13 \mathrm{~kg} / \mathrm{m}^{2}$ with any premixed insulin compared with a BMI gain of $0.3 \mathrm{~kg} / \mathrm{m}^{2}$ with biphasic insulin $50 / 50$ in the present study. This favorable effect of biphasic insulin 50/50 on weight observed in this study is supported by a previous finding from another study. Kazda et $a t^{23}$ found that, among patients who started insulin therapy with either HM50 or Humalog, BMI gain was significantly less in the former $(0.6 \pm 1.1$ vs $0.9 \pm 1.5, \mathrm{p}<0.005)$, despite patients taking a higher daily dose of insulin in the HM50 group $(0.59 \pm 0.3 \mathrm{U} / \mathrm{kg}$ vs $0.50 \pm 0.23 \mathrm{U} / \mathrm{kg}, \mathrm{p}<0.005)$. In addition, previous studies have shown benefits of HM50 compared with human insulin $70 / 30^{13}$ or Humalog $75 /$ $25^{23}$ in reducing postprandial glucose excursion. ${ }^{10}$ These benefits were augmented when HM50 was given thrice daily compared with $70 / 30$ twice daily, ${ }^{11}$ or $70 / 30$ thrice daily, ${ }^{24}$ but equivalent when compared with a basal-bolus insulin regimen. ${ }^{25}$ Our data however did not include ethnicity and hence our findings cannot be generalized to all ethnic groups. Socioeconomic factors did not affect glucose control.

In the sensitivity analysis of missing data, the association between response and baseline predictors gave similar results for the complete and incomplete cases, which indicates that missing data were unlikely to bias the outcome of the study. Nonetheless, our analyses were subject to some limitations inherent to observational studies. Potential residual confounders such as compliance, diabetes duration, indications for insulin therapy, and differences in insulin regimens or titration protocols used across different areas in the UK were not accounted for. We attempted to minimize compliance bias by restricting the analysis to those who received more than 6 months of biphasic insulin 50/50 prescription from the index date. Also, we did not fully account for the role of comorbid illnesses, but previous data suggest that this factor did not affect glycemic control. ${ }^{25}$ Despite these limitations, our study highlights the effectiveness of biphasic insulin 50/50 in real-world practice. We have shown how simple clinical and demographic parameters that are available to clinicians and researchers may influence biphasic insulin 50/50 treatment among patients with suboptimal glucose control.

In summary, the results of this study support the use of biphasic insulin 50/50 as a therapeutic option, especially among obese patients with insulin-treated diabetes whose glucose control remains suboptimal. Improvements in HbAlc were associated with weight gain and reduction in cholesterol levels. Our findings also showed that when stratified for baseline HbA1c, HM50 was associated with greater HbA1c reduction compared with IC50. A robust randomized controlled trial is required to fully investigate the effectiveness of biphasic insulin 50/50 among patients with obesity and diabetes who are unresponsive to other insulin treatment.

Contributors JM, RM, and II conceived the study, designed the methodology, and participated in the analysis and interpretation of the data. Primary analysis of the dataset was performed by JM. All authors contributed to the writing of this manuscript.

Funding This study was funded by an unrestricted grant from Eli Lilly Pharmaceutical.

Competing interests None.

Ethics approval South East REC.

Provenance and peer review Not commissioned; externally peer reviewed.

Data sharing statement No additional data are available.

Open Access This is an Open Access article distributed in accordance with the Creative Commons Attribution Non Commercial (CC BY-NC 3.0) license, which permits others to distribute, remix, adapt, build upon this work noncommercially, and license their derivative works on different terms, provided the original work is properly cited and the use is non-commercial. See: http:// creativecommons.org/licenses/by-nc/3.0/

\section{REFERENCES}

1. Raccah D. Options for the intensification of insulin therapy when basal insulin is not enough in type 2 diabetes mellitus. Diabetes Obes Metab 2008;10:76-82.

2. Turner RC, Cull CA, Frighi V, et al. Glycemic control with diet, sulfonylurea, metformin, or insulin in patients with type 2 diabetes mellitus: progressive requirement for multiple therapies (UKPDS 49). UK Prospective Diabetes Study (UKPDS) Group. JAMA 1999;281:2005-12.

3. Nathan DM, Buse JB, Davidson MB, et al. Management of hyperglycaemia in type 2 diabetes: a consensus algorithm for the initiation and adjustment of therapy. A consensus statement from the American Diabetes Association and the European Association for the Study of Diabetes. Diabetologia 2006;49:1711-21.

4. National Institute for Health and Clinical Excellence. Type 2 diabetes: newer agents 2009 [cited 19 Jul 2013]. http://www.nice. org.uk/nicemedia/live/12165/44318/44318.pdf

5. Holman RR, Farmer AJ, Davies MJ, et al. Three-year efficacy of complex insulin regimens in type 2 diabetes. $N$ Engl $J$ Med 2009;361:1736-47.

6. UK Prospective Diabetes Study (UKPDS) Group. Intensive blood-glucose control with sulphonylureas or insulin compared with 
conventional treatment and risk of complications in patients with type 2 diabetes (UKPDS 33). Lancet 1998;352:837-53.

7. Owen V, Seetho I, Idris I. Predictors of responders to insulin therapy at 1 year among adults with type 2 diabetes. Diabetes Obes Metab 2010;12:865-70.

8. Polonsky KS, Given BD, Van Cauter E. Twenty-four-hour profiles and pulsatile patterns of insulin secretion in normal and obese subjects. J Clin Invest 1988;81:442-8.

9. Herman WH, llag LL, Johnson SL, et al. A clinical trial of continuous subcutaneous insulin infusion versus multiple daily injections in older adults with type 2 diabetes. Diabetes Care 2005;28:1568-73.

10. Schwartz S, Zagar AJ, Althouse SK, et al. A single-center, randomized, double-blind, three-way crossover study examining postchallenge glucose responses to human insulin 70/30 and insulin lispro fixed mixtures 75/25 and 50/50 in patients with type 2 diabetes mellitus. Clin Ther 2006;28:1649-57.

11. Schernthaner G, Kopp HP, Ristic S, et al. Metabolic control in patients with type 2 diabetes using Humalog® Mix50 ${ }^{\mathrm{TM}}$ injected three times daily: crossover comparison with human insulin 30/70. Horm Metab Res 2004;36:188-93.

12. Shimizu $H$, Monden $T$, Matsumura $M$, et al. Effects of twice-daily injections of premixed insulin analog on glycemic control in type 2 diabetic patients. Yonsei Med J 2010;51:845-9.

13. Tanaka $M$, Ishii $H$. Pre-mixed rapid-acting insulin $50 / 50$ analogue twice daily is useful not only for controlling post-prandial blood glucose, but also for stabilizing the diurnal variation of blood glucose levels: switching from pre-mixed insulin $70 / 30$ or $75 / 25$ to pre-mixed insulin 50/50. J Int Med Res 2010;38:674-80.

14. Townsend P, Phillimore P, Beattie A. Health and deprivation: inequality and the north. London: Routledge, 1988

15. van Buuren S, Boshuizen HC, Knook DL. Multiple imputation of missing blood pressure covariates in survival analysis. Stat Med 1999;18:681-94.
16. StataCorp. Stata statistical software. Release. 13th edn. College Station, TX: StataCorp LP, 2013.

17. Ray WA. Evaluating medication effects outside of clinical trials: new-user designs. Am J Epidemiol 2003;158:915-20.

18. MacMahon S, Collins R. Reliable assessment of the effects of treatment on mortality and major morbidity, II: observational studies. Lancet 2001;357:455-62.

19. Idris I, Pillai A, Fernando DJ, et al. Responders to insulin therapy at 18 months in adults with newly diagnosed diabetes: which insulin regimen? Diabet Med 2013;30:e95-100.

20. Purnell JQ, Hokanson JE, Marcovina SM, et al. Effect of excessive weight gain with intensive therapy of type 1 diabetes on lipid levels and blood pressure: results from the DCCT. Diabetes Control and Complications Trial. JAMA 1998;280:140-6.

21. Nichols GA, Hillier TA, Javor $\mathrm{K}$, et al. Predictors of glycemic control in insulin-using adults with type 2 diabetes. Diabetes Care 2000;23:273-7.

22. Cook CB, Lyles $\mathrm{RH}$, El-Kebbi I, et al. The potentially poor response to outpatient diabetes care in urban African-Americans. Diabetes Care 2001;24:209-15.

23. Kazda C, Hulstrunk H, Helsberg K, et al. Prandial insulin substitution with insulin lispro or insulin lispro mid mixture vs. basal therapy with insulin glargine: a randomized controlled trial in patients with type 2 diabetes beginning insulin therapy. $J$ Diabetes Complications 2006;20:145-52.

24. Masuda $\mathrm{H}$, Sakamoto $\mathrm{M}$, Irie J, et al. Comparison of twice-daily injections of biphasic insulin lispro and basal-bolus therapy: glycaemic control and quality-of-life of insulin-naive type 2 diabetic patients. Diabetes Obes Metab 2008;10:1261-5.

25. El-Kebbi IM, Ziemer DC, Cook CB, et al. Comorbidity and glycemic control in patients with type 2 diabetes. Arch Intern Med 2001;161:1295-300. 